This is the Peer ReVIeWed Version of the following article: Ward, A.l., Richardson, S., Macarthur, R. AND MiLl, A.C. (2020), Using AND COMMUNICATING UNCERTAINTY FOR THE EFFECTIVE CONTROL OF INVASIVE NON-NATIVE SPECIES. MAM ReV, 50: 211-220., WHICH HAS BEEN PUBlished IN FINAL FORM AT DOI.ORG/10.1111/MAM.12188. THIS ARTICLE MAY BE USED FOR NON-COMMERCIAL PURPOSES IN ACCORDANCE With Wiley TeRms and Conditions for SelF-ARChiVING.

PERSPECTIVE

SPECIAL ISSUE ON INVASIVE MAMMAL SPECIES

\title{
Using and communicating uncertainty for the effective control of
}

\section{invasive non-native species}

Alastair I. WARD* Department of Biological and Marine Sciences, University of Hull, Cottingham

Road, Hull, HU6 7RX, UK and National Wildlife Management Centre, Animal and Plant Health Agency, National Agri-Food Innovation Campus, Sand Hutton, York, YO41 1LZ, UK. Email: a.i.ward@hull.ac.uk Suzanne RICHARDSON Department of Biological and Marine Sciences, University of Hull, Cottingham Road, Hull, HU6 7RX, UK and The Deer Initiative, The Carriage House, Brynkinalt Business Centre, Chirk, LL14 5NS, UK. Email: s.richardson2@hull.ac.uk

Roy MACARTHUR Fera Science Ltd., National Agri-Food Innovation Campus, Sand Hutton, York, YO41 1LZ, UK. Email: roy.macarthur@fera.co.uk

Aileen C. MILL School of Natural and Environmental Sciences, Newcastle University, Newcastle upon Tyne, NE1 7RU, UK. Email: aileen.mill@newcastle.ac.uk

\section{ABSTRACT}

Estimates of quantities needed to plan invasive species control, such as population size, are always uncertain; this is an issue that can become a problem when mishandled in ecological science and its communication. The complexities of incorporating uncertainty into sophisticated decision-support tools may be a barrier to their use by decision-makers, leading to decisions being 
made without due regard to uncertainty and risking mis-placed certainty of predicted outcomes.

We summarise ways in which uncertainty has been incorporated into and used to advise decisions on the management of invasive non-native species and other problem species, and offer a simple conceptual model for accommodating and using uncertainty at the planning stage. We also demonstrate how frequently uncertainty has been mis-used and mis-communicated in the wildlife management literature. We contend that uncertainty in estimates of natural quantities must be acknowledged, can inform decisions and can be made to derive decisions, and should not be ignored if invasive species policy is to be delivered effectively. Uncertainty must be communicated thoroughly and correctly by scientists if decision-makers are to understand its consequences for planning and resourcing control programmes.

Keywords: confidence interval, decision-making, error, invasive non-native mammals, probability, wildlife management

Running head: Uncertainty in non-native species management

* Correspondence author

Received: 8 April 2019

Accepted: 19 December 2019

Editor: DR

Special Issue Guest Editor: Sandro Bertolino

\section{INTRODUCTION}

Decisions regarding responses to invasive non-native species (hereafter referred to as invasives) are fraught with uncertainty. During the early stages of invasion, detection probability is likely to be low due to the species' very limited spatial range and low abundance (Mehta et al. 2007), leading to highly uncertain estimates of these quantities (Wenger \& Freeman 2008). As the range expands and the population grows, the species may be detected more frequently. However, estimates remain uncertain, as evinced by the broad confidence intervals that typically define population estimates of new 
invaders and other low-density populations (Miller et al. 2005), with consequent uncertainty regarding the effort required to control them (Johnson et al. 2017). Even when widely established and highly abundant, estimation of a species' range, population size, and population growth to magnitudes of accuracy and precision that can be accommodated by traditional approaches to management planning can be challenging due to large uncertainties associated with limited sampling (Mackenzie 2005). This is problematic because comprehensive information on populations is required to improve the likelihood of success of management campaigns against invasives (Simberloff 2003). Policy-makers often seek certainty and simplicity from those experts chosen to provide policy-relevant evidence (Hammersely 2013). However, uncertainty in natural quantities, such as range and abundance, which can be used to inform management decisions can present significant challenges for decision-makers, because uncertainty makes the prediction of the outcomes, for a given investment, uncertain and imprecise (Nair \& Howlett 2017). In consequence, decision-makers may ignore uncertainty, dismissing it as an inconvenient impediment to necessary action (Hammersely 2013), choosing instead to rely on subjective judgement (Regan et al. 2005). Many experts, including applied ecologists, who may advise decision-makers also have a history of mishandling uncertainty (Milner-Gulland \& Shea 2017), which may compound this problem. A wide range of quantitative tools has been developed to incorporate uncertainty into decisions, including those pertaining to the control of invasives, yet uptake of these has typically been very low (Addison et al. 2013). A substantial number of campaigns against invasives have either failed (Pluess et al. 2012, Capizzi et al. 2020) or cost much more than originally anticipated (see Parkes et al. 2010, Mill et al. 2020), possibly due to a failure to incorporate uncertainty into management decisions adequately. While decision-makers may view uncertainty and complexity in estimates of natural quantities as unhelpful and indicative of the low quality or incredibility of available information (Hammersely 2013), we contend that the appropriate management of uncertainty can help inform campaigns against invasives better than if uncertainty was ignored (Funtowicz \& Ravetz 1990). 


\begin{abstract}
AIMS
In this article, we sought to summarise what uncertainty is with respect to estimates of natural populations and processes, evaluate how uncertainty has been used and communicated in the wildlife management literature, and synthesise some simple principles for using and reporting uncertainty during the planning stage of campaigns against invasives and other wildlife species that people wish to control. There are many ways in which uncertainty can be incorporated into decision-making; the list of approaches described below is not exhaustive, and those that are advocated are simply those that we have found helpful when planning wildlife management programmes and communicating those plans with decision-makers and other stakeholders.
\end{abstract}

\title{
DEFINING UNCERTAINTY
}

The many sources of uncertainty in biological systems and models of them have long been recognised and incorporated into decision-making processes by fisheries scientists (see Hilborn \& Walters 1992), and are increasingly considered within literature on the management of terrestrial vertebrates (Milner-Gulland \& Shea 2017, Nichols 2019). In their seminal review, Regan et al. (2002) classified two main branches in the taxonomy of uncertainty as it arises in ecology and conservation biology: epistemic and linguistic uncertainty.

Epistemic uncertainty refers to the state of a system, and is due to the limitations of measuring instruments, natural variability within the system, inadequate sampling, and extrapolation and interpolation. Thus, epistemic uncertainty encompasses the accuracy and precision of inputs or measurements, and outputs or estimates (Nichols 2019). It can be characterised by describing measurement precision and sample size, quantifying measurement variability (see Box), stating and evaluating the assumptions underpinning calculations, interpolations or extrapolations, and by bias-correction when appropriate. It can be quantified (e.g. as confidence intervals) or described as a probability (i.e. of the null hypothesis being incorrect; Regan et al. 2002). The former is perhaps the most traditional approach employed widely in ecology, whereas uptake of the latter has perhaps been 
more recent, increasing particularly with the incorporation of Bayesian statistics into ecological studies.

Linguistic uncertainty arises from poor communication; language can be unspecific, ambiguous, vague and context-dependent. Borrowing from Regan et al. (2002), the importance of good communication for the minimisation of uncertainty is evident when considering the aim of an invasives control programme. If we wish to eradicate all invasives from an area, we must define precisely a) what invasives are so that we can determine which species to focus on, and b) what the area is.

Epistemic and linguistic uncertainty, alone and acting together, can result in model or outcome uncertainty, whereby the consequences of an action can be quite different to what was predicted due to complexities within the system (Regan et al 2002, Artelle et al. 2013).

\section{COMMUNICATING UNCERTAINTY}

It is important that uncertainty is communicated well by scientists to decision-makers so that management decisions can be more fully informed, but its reporting in the applied ecology literature is inconsistent. This failure to report uncertainty correctly is an important additional aspect of linguistic uncertainty to those described by Regan et al. (2002). Standard statistical terms used to evaluate different components or characteristics of uncertainty, such as the standard deviation of a sample mean and the standard error of a parameter estimate, may be reported in ways that are inconsistent with definitions given in basic statistical text books. To test this statement we evaluated the reporting of uncertainty in 98 published scientific papers on adaptive wildlife management (see Appendices S1 and S2). Among 65 articles reporting estimates, 17\% did not report averages and 35\% did not report measurement variability or estimate uncertainty. Instead of averages, other less useful metrics, such as minimum count, which does not account for detection probability, were reported. Among 63 of these articles, $35 \%$ should have used an average descriptor other than the mean because data were not normally distributed or sample sizes were small. Among these 63 articles, $43 \%$ reported the correct 
descriptor of measurement variability or estimate uncertainty, but only $17 \%$ sought to interpret the effect of estimated uncertainty quantitatively, and 29\% qualitatively. Milner-Gulland and Shea (2017) stated that applied ecologists have often been guilty of ignorance, disregard and hubris in relation to uncertainty, and our results are consistent with this view. It should be no surprise that policy-makers, politicians and other decision-makers misunderstand and miscommunicate uncertainty when their expert advisors are equally guilty. We recommend that applied ecologists should adhere to the definitions of measures of uncertainty described in standard statistical text books (see Box), and should use them correctly in all communications.

\section{UNCERTAINTY IN DECISION-MAKING}

Many approaches exist for incorporating uncertainty into model outputs in applied ecology (Nichols 2019), and yet its importance for decision-making can be over-looked (Milner-Gulland \& Shea 2017). For example, Wäber et al. (2013) estimated that, despite culling, a mean of 1103 Reeves' muntjac Muntiacus reevesi was recruited to an English plantation forest during 2008/2009 and 1287 during 2009/2010. A traditional approach to cull target setting might therefore have recommended removal of approximately 1100-1300 extra muntjac per year in order to halt population growth and prevent emigration. However, the $95 \%$ confidence interval for estimated recruitment was 21 to 2284 and 238 to 1783 muntjac in each year, respectively. Consequently, and accepting the validity of the assumptions underpinning the calculations, forest managers would have had to remove somewhere between these ranges of values to achieve their objective. The immediate problem is understanding where, within those ranges, the true number of muntjac that needed to be removed lies. The simple and unsatisfactory answer is that it is impossible to know. However, appropriate handling of estimate uncertainty can enable such decisions by reducing the risk of objective failure.

Milner Gulland and Shea (2017) and Nichols (2019) summarised a range of methodological options for minimising and incorporating uncertainty in scientific and modelling exercises, and reviewed a number of approaches to including uncertainty in management and decision-making. These included stochastic dynamic programming and partially observable Markov decision processes. We do not 
dispute the suitability of the solutions described by these authors, who provided examples of conservation and wildlife management interventions where they have usefully been employed, but we do question the extent of their utility. Artelle et al. (2018) found that the hallmarks of quality science were absent from the majority of 667 wildlife management approaches adopted in North America. This is likely to be due to the complexity of biological systems and the way in which scientists describe them, resulting in decision-makers avoiding the use of robust scientific approaches for decision-making (Addison et al. 2013, Hammersley 2013). Indeed, the approach adopted by the UK government for the prioritisation of invasives for eradication under uncertainty is intuitive, qualitative and based on expert opinion (Booy et al. 2017), and does not incorporate quantitative models of ecological processes. Consequently, while we endorse the recommendations of Addison et al. (2013) for improving the uptake of ecological models for applied decision-making (see also Richardson et al. 2020, Bertolino et al. 2020), we nevertheless recommend simpler approaches for the inclusion, reporting and use of uncertainty to address perhaps the most simple and, in our experience, most frequently asked questions at the outset of invasives control programmes: how should we prioritise potential invasives prior to their arrival, is a priority species present, how is it distributed, how abundant is it, how many must be removed to control it and how much will a control programme cost? These questions, unsurprisingly, relate directly to the established approaches to controlling invasives, which are, in order of priority: prevention of invasion, rapid response to prevent establishment, eradication to reverse an invasion, and ongoing control of established populations (Simberloff 2003; Table 1).

\section{Uncertainty in species prioritisation prior to invasion}

In advance of invasion, knowledge of the risks that might be posed to anthropocentric or biodiversity interests will be limited to that available for a species' existing range. Consequently, extrapolation of the likely risks to the country to be invaded will result in uncertainty in outputs for that country. The requirement for horizon-scanning to enable evaluation of the likely risks posed (Roy et al. 2014) has led to the use of expert elicitation to populate risk assessments, with uncertainty characterised 
subjectively as an uncertainty score (Mumford et al. 2010). This can result in bias and mis-representation of uncertainty (Kynn 2008), but has been used to prioritise potential invaders according to the relative risks they may pose (Mumford et al. 2010) and the relative feasibility of control methods for eradicating them should they invade (Booy et al. 2017).

\section{Uncertainty in species presence and distribution}

Once prioritised for action, early detection of an invasive is necessary in order to prevent its establishment (Simberloff 2003). However, surveys designed to detect an invasion with a high probability have hitherto been extremely costly, since the invasives are likely to be highly geographically constrained and at low density during the early stages, leading to the conundrum of whether to invest more in detection or control (Mehta et al. 2007). The advent of novel detection techniques such as environmental DNA metabarcoding may reduce these costs substantially (Browett et al. 2020). Nevertheless, while the detection of a single individual or population may confirm that an invasion is underway, it does not explain the geographical extent of the invasion, and hence the area over which control is required. In contrast, the failure to detect an individual or population makes the conclusion of presence or absence highly uncertain, since surveys may suffer an inadequate detection probability (Christy et al. 2010). Occupancy estimation and modelling, which adopts the probabilistic approach to uncertainty characterisation (Mackenzie et al. 2017) can be used to address some of these problems. The underlying principles of occupancy estimation are that the probability of detecting a species increases with survey effort, and the detection probability for a single survey can be estimated. The probability of failing to detect a species, if it is present, decreases as the number of surveys increases such that, with sufficient surveys, this probability crosses a threshold (traditionally 0.95 ) that can be set by the user according to their attitude towards risk. Thus, with sufficient surveys (as defined by the detection probability and the threshold), failure to detect a species can be interpreted as likely absence, with a given probability defining the uncertainty. The same approach can be used in multiple locations to estimate the proportion of sites likely to be occupied and hence the area over which control may be required (Mackenzie et al. 2017). The concept of occupancy estimation is 
straight-forward, and the principle of characterising uncertainty probabilistically is intuitive, and hence may be easy to convey to decision-makers. However, the calculations are rather more complicated and so employment of this approach may be best suited to technical specialists.

\section{Uncertainty in species abundance}

Where eradication or ongoing management of populations are the selected approaches, estimates of management effort are usually required (McCann \& Garcelon 2008); for medium to large mammals, these often require estimates of the number of animals to be removed and the proportion of the population that this target represents. Numerous methods for abundance estimation are available (for carnivores, see Wilson \& Delahay 2001), but particularly for an eradication campaign during a single year, total population size should be estimated, since it equates to the number that must be removed in advance of the birthing season.

Regardless of the method chosen, and in addition to the assumptions on which calculations are based, uncertainty in population size can be quantified probabilistically or as a range of values. The probabilistic approach can be followed to evaluate whether uncertainty is tolerable. For example, if a requirement is to be $90 \%$ certain that a species' population is above a certain size, then a probability of 0.9 or more that the population estimate is correct, or conversely, a probability of 0.1 or less that it is incorrect, is sufficient to evaluate whether a policy objective is likely to be met. However, this approach cannot inform us how to use the uncertainty to set targets. To use uncertainty to reduce the risk of failing to achieve a management objective for invasives at the planning stage, uncertainty is best described as the confidence interval defining the estimated outputs (see below).

\section{Uncertainty in cost of species control}

Arguably, the most important component of an invasives management plan is an estimate of the likely financial cost of control, since this facilitates evaluation of the cost-effectiveness of the options 
available (Buhle et al. 2004). The costs of control relate to the size of the population, the species' life history (particularly as it relates to the population growth rate), the proportion of the population removed per unit effort and the cost per unit effort (Buhle et al. 2004, Ward \& Lees 2011).

\section{Uncertainty in the number to remove}

Assuming that doing nothing is not an option if the objective is control of an invasive, the remaining options are to prevent population growth and spread, to reduce the population size, or to eradicate the species. The containment or eradication of an invasive (or any species) requires the removal of at least the number of females that is recruited to the population each year (Fryxell et al. 2014). For animals, the number to be removed has been calculated as the product of female population size at a point in time and female recruitment rate (the number of female offspring produced per female during the season), assuming that the mean of each of these values (the thin dashed lines A and B respectively in Fig. 1) offers an approximate estimate of the minimum number that must be taken (Buckland et al. 1996, Wäber et al. 2013). However, this approach suffers a high risk of failure because it ignores uncertainty in parameter estimates. Estimates of both quantities are uncertain, characterised as confidence intervals (the range between the thick dashed lines either side of A and B, Fig. 1). Line C is midway among the combined uncertainties; products of population size and recruitment rate point estimates along this line are equal to the value derived from the means of these variables (point d). Assuming an unbiased distribution of values around the mean, it should be clear that very nearly $50 \%$ of credible values of the number of females recruited lie to the left of line C, nearly $50 \%$ lie to the right of it and very few lie along it. Removal of the mean number of females recruited as a management objective has an approximately $50 \%$ chance of being too few, and a vanishingly small chance of being correct. Consequently, to be confident of removing at least the number of females recruited to the population, minimum cull targets should be set conceptually at point e, the product of the upper confidence limits of female population size and female recruitment rate estimates. The degree of confidence that must be afforded to the calculation of this value, i.e. the proportion of values likely to be contained within the interval, must be determined by the decision-maker's acceptance of 
the risk of failing to at least prevent population growth. For example, using $80 \%$ confidence intervals, and assuming an unbiased distribution, $10 \%$ of credible values will be to the left of the lower limit, and $10 \%$ will be to the right of the upper limit. Thus, risk-accepting decision-makers may choose a smaller confidence interval and risk-averse decision-makers may choose a larger one. This approach does not guarantee that the population will decline if the target is achieved, but, as long as the assumptions underpinning the calculations are correct, it substantially reduces the risk of under-culling from 50:50.

The opposite application of this approach is for the sustainable harvesting of a species. To ensure that populations persist, the maximum number of females that should be harvested is conceptually set at point $f$, i.e. the product of the lower confidence limits of female population size and female recruitment rate. This should ensure that no more than the number of females recruited to the population is removed during a single harvesting season (see Artelle et al. 2013).

Estimate uncertainties cannot simply be multiplied in the way implied by this concept since it will lead to over-estimation of uncertainty, instead they must be combined into a single estimate. This can be achieved by a number of methods (Nichols 2019) including Monte Carlo simulation: a single value is drawn at random from the confidence interval of female population size, and multiplied by a single value drawn at random from the confidence interval of the female recruitment rate, and the process is repeated a large number of times. The mean and standard deviation of the large number of outputs are used to calculate the confidence interval in the normal way. The upper limit of this interval corresponds to point e and the lower limit to point $f$ on Fig. 1.

Johnson et al. (2017) developed a multi-step modelling approach to estimate the effort and hence costs of invasive non-native tegu lizard Salvator merianae control in Florida, USA. Demographic rates were summarised by repeatedly sampling point estimates derived by expert elicitation, to build population matrices that were scenario-tested for the likely cost and effectiveness of different control strategies. Scenario planning is an informative way of planning control campaigns against invasives at the outset, when planners are information-poor, and can help improve prioritisation of parameters for uncertainty reduction (Peterson et al. 2003). Moreover, the utility of this approach can be 
complemented by including consideration of uncertainty, not just when deriving parameter estimates, but when interpreting model outputs too.

An example is provided by the ongoing control of feral wild boar Sus scrofa in western England, for which the objective has been the prevention of population growth. Boar density, total abundance and population growth rate have been estimated annually since 2013, in order to advise single-year cull targets to prevent population growth (Table 2). A cull of $56.5 \%$ of the population was estimated to be required to prevent growth during 2015 and 2016 (Gill \& Ferryman 2015, Gill \& Waeber 2016). The method for calculating this cull target was not reported, but targets can be calculated from the average of the estimated female recruitment rate and female population size during each year. As argued above, we suggest that this approach has a high risk of under-culling during a given year, and hence might have contributed to the sustained trend of population growth.

Following the approach that we have advocated (Fig. 1), and accepting all assumptions underpinning calculations of wild boar population size, structure and productivity as correct, we combined estimates of female population sizes (values in Table 2 divided by two, to reflect the reasonable assumption of a 1:1 sex ratio; Keuling et al. 2003) with estimates of female recruitment rates (which were not reported for this population, and hence were summarised from other European populations as varying from 0.85 to 1.63 ; Bieber \& Ruff 2005). Assuming a uniform distribution for both parameters, and with 1000 iterations in the Monte Carlo simulation, we estimate that female cull targets should have been much higher. During 2014, the number of females recruited was between 560 and 585 (95\% confidence interval), so a risk-averse minimum cull target would have been 585 female wild boar. During 2015, recruitment of 657-680 required a minimum target of 680, and during 2016 and 2018, recruitment of 1040-1073 during both years required a minimum target of 1073. Of course, these values might be biased high or low if the assumption of a 1:1 sex ratio was incorrect or if any of the other assumptions underpinning the calculations were violated. These cull targets either exceed or are very close to the lower confidence limit of the population size estimate, and so might be impossible or extremely challenging to achieve. Achievement of our revised target during 2014 might have caused 
the eradication of the population. This would not be a problem if sufficient resources had been made available to remove those numbers from a population of invasives; it may in fact have been a benefit.

\section{Uncertainty in the costs of removal}

Estimating the costs of control according to worst-case scenarios should ensure that management campaigns are not under-resourced. In a modelling study of a range of hypothetical population sizes, Ward and Lees (2011) estimated that the eradication of populations of 200 Reeves' muntjac from Scotland, should they become established (which they are not, despite being widely established in England and Wales; Ward 2005), was likely to cost an average of GB£24050, but might cost as much as GB£60625, and advocated budgeting according to the latter figure. While this might be viewed as inefficient and risking resource not be available for other campaigns, it is likely to be more cost-effective than budgeting on averages, which, all else being equal, should result in their main objective not being met approximately $50 \%$ of the time, and may require additional resource to respond to population growth during subsequent years (see Parkes et al. 2010; Mill et al 2020). Indeed, under-resourcing has been one of the main factors associated with the failure of invasives control in New Zealand (Brown et al. 2015). However, risks associated with this approach include forecasting such high estimated costs that decision-makers decide that doing nothing or some lesser intervention is preferable, undermining the morale of operatives controlling populations of invasives as they toil towards an unattainable target.

\section{SOLUTIONS TO UNCERTAINTY FOR THE CONTROL OF INVASIVES}

Solutions to the issue of uncertainty in ecological science and decision-making have been summarised by several authors (including Regan et al. 2002, Milner-Gulland \& Shea 2017, Nichols 2019), but have rarely been adopted for the control of invasives. We should accept that all of our estimates and hence predicted management outcomes are, under nearly all circumstances and particularly at the start 
of a management campaign, highly uncertain, and should respond accordingly. This requires working with uncertainty at all levels:

1) Researchers who estimate quantities should calculate, interpret and communicate uncertainty as fully and as simply as possible, and always accurately, so that decision-makers can respond appropriately.

2) Decision-makers should understand uncertainty, how to ensure it is included in decision-making processes, and how to work with it or use it to define desirable (and undesirable) outcomes.

3) Managers should incorporate uncertainty into management objectives, including targets, and should communicate this uncertainty to operatives, in order to manage expectations with regards to delivery.

4) Finally, operatives need to understand what uncertainty is and what its implications are for management, so that they can help managers evaluate outcomes, and so that they can manage their own expectations with regards to target achievement.

There is no single approach for incorporating uncertainty into decision-making that is universally applicable to all stages of the invasion process, and different approaches may be demanded to inform effective action at each stage. We advocate the following:

1) Prior to invasions, existing information can be used to inform risk assessments (Mumford et al. 2010) and risk management evaluations (Booy et al 2017), and uncertainty should be semi-quantified into confidence scores by expert opinion in order to prioritise potential invasives for eradication. These processes have been specifically designed to facilitate decision-making by non-specialists.

2) When an invasion is suspected, or if confirmation of the likely absence of a potential invader is required, occupancy estimation can be used to quantify the probability of absence and likely geographic range of the invasive, with uncertainty estimated probabilistically (Mackenzie et al. 2017). The principles of this approach are intuitive, but the complexities of 
its deployment mean that its use is probably best-suited to specialists who advise decision-makers.

3) To inform plans to eradicate an invasive, estimates of population size and geographical range will be required to estimate the management effort required and hence the total cost of control. We recommend a precautionary approach such that the upper limits of population size and range are used to estimate costs, with the limits defined by the decision-maker's attitude to risk.

4) For the ongoing control of established invasives, we recommend combining the upper limits of estimated female population size and female recruitment rate to derive minimum female cull targets, with limits defined by the decision-maker's attitude to risk. This precautionary approach is simple and intuitive, but it risks over-budgeting and hence culling more than is strictly necessary to prevent population growth or spread.

\section{CONCLUSION}

There has been a tendency for applied ecologists to mis-handle uncertainty when advocating or planning management action, and uncertainty has rarely been incorporated adequately into management campaigns against invasives. It is clear that point estimates, including averages of estimates, are very nearly always wrong, and using average point estimates to set management objectives for the control of invasives poses a high risk of failure. It is also clear that the approach that we recommend for using uncertainty to plan campaigns against invasives assumes the worst case, and hence is likely to produce targets that might be unattainable. Nevertheless, we argue that this approach offers a helpful first step for planning management campaigns, because it should ensure that sufficient resource is available at the outset to deliver the management objective. However, funding sources are always finite (Mill et al. 2020), and pressure is likely to be exerted on campaign managers to find cost savings as campaigns progress (Carrion et al. 2011); such cost savings could be driven by reducing the uncertainty of the scale of the problem being addressed (Milner-Gulland \& Shea 2017). Uncertainty can be reduced by collecting information on management inputs and outcomes as a campaign progresses, such that estimates of resource requirements and hence definitions of objectives can be 
refined. The cyclical process of setting objectives, predicting outcomes, delivering management action, simultaneously undertaking monitoring, evaluating inputs and outputs, learning about the system under management and hence refining objectives and actions sequentially is termed adaptive natural resource management (Williams 2011). This approach has been adopted by many people intending to manage invasives, with varying degrees of diligence (Richardson et al. 2020). The concept of acknowledging and using uncertainty that we advocate for decision-making, applied to the principles of incorporating uncertainty into estimates of natural quantities summarised by Regan et al. (2002) and Nichols (2019) offers the ability to set clear, unambiguous, evidence-based management targets at the very start of campaigns against invasives, and at every stage at which new information arises and hence at which uncertainty is reduced.

\section{ACKNOWLEDGEMENTS}

This study was partially supported by InnovateUK under Knowledge Transfer Partnership 10776. We are grateful to two anonymous reviewers and the guest editor for helpful comments to improve the focus and inclusivity of the manuscript.

\section{REFERENCES}

Addison PF, Rumpff L, Bau SS, Carey JM, Chee YE, Jarrad FC, McBride MF, Burgman MA (2013) Practical solutions for making models indispensable in conservation decision-making. Diversity and Distributions 19: 490-502.

Artelle KA, Anderson SC, Cooper AB, Paquet PC, Reynolds JD, Darimont CT (2013) Confronting uncertainty in wildlife management: performance of grizzly bear management. PloS ONE 8: e78041.

Artelle KA, Reynolds JD, Treves A, Walsh JC, Paquet PC, Darimont CT (2018) Hallmarks of science missing from North American wildlife management. Science Advances 4: eaao0167. 
Bertolino S, Sciandra C, Bosso L, Russo D, Lurz P, Di Febbraro M (2020) Spatially explicit models as tools for implementing effective management strategies for invasive alien mammals. Mammal Review 50: in press.

Bieber C, Ruf T (2005) Population dynamics in wild boar Sus scrofa: ecology, elasticity of growth rate and implications for the management of pulsed resource consumers. Journal of Applied Ecology 42: 1203-1213.

Booy O, Mill AC, Roy HE, Hiley A, Moore N, Robertson P et al. (2017) Risk management to prioritise the eradication of new and emerging invasive non-native species. Biological Invasions 19: 2401-2417.

Browett SS, O’Meara DB, McDevitt AD (2020) Genetic tools in the management of invasive mammals: recent trends and future perspectives. Mammal Review 50: in press.

Brown K, Elliott G, Innes J, Kemp J (2015) Ship Rat, Stoat and Possum Control on Mainland New Zealand. An Overview of Techniques, Successes and Challenges. Department of Conservation, Wellington, New Zealand.

Buckland ST, Ahmadi S, Staines BW, Gordo IJ, Youngson RW (1996) Estimating the minimum population size that allows a given annual number of mature red deer stags to be culled sustainably. Journal of Applied Ecology 33: 118-130.

Buhle ER, Margolis M, Ruesink JL (2005) Bang for buck: cost-effective control of invasive species with different life histories. Ecological Economics 52: 355-366.

Capizzi D (2020) A review of mammal eradications on Mediterranean islands. Mammal Review 50: in press.

Carrion V, Donlan CJ, Campbell KJ, Lavoie C, Cruz F (2011). Archipelago-wide island restoration in the Galápagos Islands: reducing costs of invasive mammal eradication programs and reinvasion risk. PloS ONE 6: e18835. 
Christy MT, Yackel Adams AA, Rodda GH, Savidge JA Tyrrell CL (2010) Modelling detection probabilities to evaluate management and control tools for an invasive species. Journal of Applied Ecology 47: 106-113.

Fowler J, Cohen L, Jarvis P $\left(1998,2^{\text {nd }}\right.$ ed.) Practical Statistics for Field Biology. John Wiley and Sons Ltd., Chichester, UK.

Fryxell JM, Sincalir ARE, Caughley G (2014) Wildlife Ecology, Conservation and Management. John Wiley \& Sons Ltd, Chichester, UK.

Funtowicz SO, Ravetz JR (1990) Uncertainty and Quality in Science for Policy. Kluwer Academic Publishers, Dordrecht, The Netherlands.

Gill R (2014) Wild boar and deer in the Forest of Dean 2014. Forest Research, Wrecclesham, UK. https://www.forestresearch.gov.uk/research/management-of-non-native-or-invasive-vertebrates/resear ching-management-of-feral-wild-boar/

Gill R, Ferryman M (2015) Feral wild boar and deer in the Forest of Dean. Population surveys in the public forest estate 2015. Forest Research, Wrecclesham, UK.

https://www.forestresearch.gov.uk/research/management-of-non-native-or-invasive-vertebrates/resear ching-management-of-feral-wild-boar/

Gill R, Waeber K (2016) Feral wild boar and deer in the Forest of Dean. Population surveys in the public forest estate 2016. Forest Research, Wrecclesham, UK.

https://www.forestresearch.gov.uk/research/management-of-non-native-or-invasive-vertebrates/resear ching-management-of-feral-wild-boar/

Gill R, Waeber K (2018) Feral wild boar and deer in the Forest of Dean. Population surveys in the public forest estate 2018. Forest Research, Wrecclesham, UK. https://www.forestryengland.uk/sites/default/files/documents/Feral\%20Wild\%20Boar\%20Deer\%20De an\%20Census $\% 202018$.pdf 
Hammersely M (2013) The Myth of Research-based Policy and Practice. Sage Publications, London, UK.

Hilborn R, Walters CJ (1992) Quantitative Fisheries Stock Assessment: Choice, Dynamics and Uncertainty. Chapman and Hall, London.

Johnson FA, Smith BJ, Bonneau M, Martin J, Romagosa C, Mazzotti F, Waddle H, Reed RN, Eckles JK, Vitt LJ (2017) Expert elicitation, uncertainty, and the value of information in controlling invasive species. Ecological Economics 137: 83-90.

Keuling O, Baubet E, Duscher A, Ebert C, Fischer C, Monaco A et al. (2013) Mortality rates of wild boar Sus scrofa L. in central Europe. European Journal of Wildlife Research 59: 805-814.

Kynn M (2008) The 'heuristics and biases' bias in expert elicitation. Journal of the Royal Statistical Society: Series A (Statistics in Society) 171: 239-264.

MacKenzie DI (2005) What are the issues with presence-absence data for wildlife managers? The Journal of Wildlife Management 69: 849-860.

MacKenzie DI, Nichols JD, Royle JA, Pollock KH, Bailey L, Hines JE (2017, $2^{\text {nd }}$ ed.) Occupancy Estimation and Modeling: Inferring Patterns and Dynamics of Species Occurrence. Elsevier, London, UK.

McCann BE, Garcelon DK (2008) Eradication of feral pigs from Pinnacles National Monument. The Journal of Wildlife Management 72: 1287-1295.

Mehta SV, Haight RG, Homans FR, Polasky S, Venette RC (2007) Optimal detection and control strategies for invasive species management. Ecological Economics 61: 237-245.

Mill AC, Crowley SL, Lambin X, McKinney C, Maggs G, Robertson P, Robinson NJ, Ward A, Marzano M (2020) The challenges of long-term invasive mammal management: lessons from the UK. Mammal Review 50: in press. 
Miller CR, Joyce P, Waits LP (2005) A new method for estimating the size of small populations from genetic mark-recapture data. Molecular Ecology 14: 1991-2005.

Milner-Gulland EJ, Shea K (2017). Embracing uncertainty in applied ecology. Journal of Applied Ecology 54: 2063-2068.

Mumford J, Booy O, Baker R, Rees M, Copp GH, Black K, Holt J, Leach A, Hartley M (2010) Invasive non-native species risk assessment in Great Britain. Aspects of Applied Biology 104: 49-54.

Nair S, Howlett M (2017) Policy myopia as a source of policy failure: adaptation and policy learning under deep uncertainty. Policy \& Politics 45: 103-118.

Nichols JD (2019) Confronting uncertainty: contributions of the wildlife profession to the broader scientific community. The Journal of Wildlife Management 83: 519-533.

Parkes JP, Ramsey DS, Macdonald N, Walker K, McKnight S, Cohen BS, Morrison SA (2010) Rapid eradication of feral pigs (Sus scrofa) from Santa Cruz Island, California. Biological Conservation 143: 634-641.

Peterson GD, Cumming GS, Carpenter SR (2003) Scenario planning: a tool for conservation in an uncertain world. Conservation Biology 17: 358-366.

Pluess T, Jarošík V, Pyšek P, Cannon R, Pergl J, Breukers A, Bacher S (2012) Which factors affect the success or failure of eradication campaigns against alien species? PloS ONE 7: e48157.

Regan HM, Ben-Haim Y, Langford B, Wilson WG, Lundberg P, Andelman SJ, Burgman MA (2005) Robust decision-making under severe uncertainty for conservation management. Ecological Applications 15: 1471-1477.

Regan HM, Colyvan M, Burgman MA (2002) A taxonomy and treatment of uncertainty for ecology and conservation biology. Ecological Applications 12: 618-628. 
Richardson S, Mill A, Davis D, Jam D, Ward AI (2020) A systematic review of adaptive wildlife management for the control of invasive, non-native mammals and other human-wildlife conflicts. Mammal Review 50: in press.

Roy HE, Peyton J, Aldridge DC, Bantock T, Blackburn TM, Britton R et al. (2014) Horizon scanning for invasive alien species with the potential to threaten biodiversity in Great Britain. Global Change Biology 20: 3859-3871.

Simberloff D (2003) How much information on population biology is needed to manage introduced species? Conservation Biology 17: 83-92.

Wäber K, Spencer J, Dolman PM (2013) Achieving landscape-scale deer management for biodiversity conservation: the need to consider sources and sinks. The Journal of Wildlife Management 77: 726-736.

Ward AI (2005) Expanding ranges of wild and feral deer in Great Britain. Mammal Review 35: $165-173$.

Ward AI, Lees K (2011) Analysis of Cost of Preventing Establishment in Scotland of Muntjac Deer (Muntiacus spp.). Commissioned Report 457, Scottish Natural Heritage, Edinburgh, UK.

Wenger SJ, Freeman MC (2008) Estimating species occurrence, abundance, and detection probability using zero-inflated distributions. Ecology 89: 2953-2959.

Williams BK (2011) Adaptive management of natural resources - framework and issues. Journal of Environmental Management 92: 1346-1353.

Wilson GJ, Delahay RJ (2001) A review of methods to estimate the abundance of terrestrial carnivores using field signs and observation. Wildlife Research 28: 151-164. 
Table 1. Some major sources of uncertainty and ways in which they can be incorporated into decisions regarding the control of invasive non-native species during each stage of the invasion process.

\begin{tabular}{|c|c|c|c|c|c|}
\hline \multirow[t]{2}{*}{ Stage } & \multicolumn{2}{|c|}{ Input uncertainties } & \multicolumn{2}{|c|}{ Output uncertainties } & \multirow[t]{2}{*}{ References } \\
\hline & Source & How to incorporate & How to report & How to use & \\
\hline \multirow[t]{2}{*}{$\begin{array}{l}\text { Prior to } \\
\text { invasion }\end{array}$} & $\begin{array}{l}\text { List of risks. } \\
\text { Factors contributing }\end{array}$ & $\begin{array}{l}\text { Synthesis of existing } \\
\text { information. }\end{array}$ & Risk score. & $\begin{array}{l}\text { Prioritisation of species by risk and } \\
\text { feasibility of control. }\end{array}$ & $\begin{array}{l}\text { Mumford et al. } 2010 \\
\text { Booy et al. } 2017\end{array}$ \\
\hline & $\begin{array}{l}\text { to likelihood and } \\
\text { severity of risk. } \\
\text { Feasibility of control. }\end{array}$ & & $\begin{array}{l}\text { Qualitative assessment of } \\
\text { confidence in risk score. }\end{array}$ & $\begin{array}{l}\text { Identification of areas for further research } \\
\text { to reduce uncertainty. }\end{array}$ & \\
\hline $\begin{array}{l}\text { Suspected } \\
\text { invasion }\end{array}$ & Presence/absence. & $\begin{array}{l}\text { Occupancy analysis of } \\
\text { surveillance data. }\end{array}$ & $\begin{array}{l}\text { Presence (if detected) or } \\
\text { probability of absence. }\end{array}$ & $\begin{array}{l}\text { Confirmation of presence. } \\
\text { Acceptance of absence probability. } \\
\text { Confirmation of requirement for further } \\
\text { surveillance if probability of absence is } \\
\text { below the acceptable threshold. }\end{array}$ & Mackenzie et al. 2017 \\
\hline \multirow[t]{4}{*}{$\begin{array}{l}\text { Confirmed } \\
\text { invasion } \\
\text { (early) }\end{array}$} & Distribution. & $\begin{array}{l}\text { Occupancy analysis of } \\
\text { surveillance data. }\end{array}$ & $\begin{array}{l}\text { Proportion of locations } \\
\text { likely to be occupied with a } \\
\text { given probability. }\end{array}$ & $\begin{array}{l}\text { Map likely distribution to prioritise } \\
\text { surveillance and control. }\end{array}$ & Mackenzie et al. 2017 \\
\hline & Population size. & Sampling error (mean & $\begin{array}{l}\text { Confidence interval of } \\
\text { population size estimate. }\end{array}$ & $\begin{array}{l}\text { Assume worst case: population defined } \\
\text { by upper confidence limits. }\end{array}$ & \\
\hline & & & & & Ward \& Lees 2011 \\
\hline & Number to remove. & $\begin{array}{l}\text { Combine abundance } \\
\text { with recruitment rate. }\end{array}$ & $\begin{array}{l}\text { Confidence interval of } \\
\text { number of recruits. }\end{array}$ & $\begin{array}{l}\text { Set cull target according to worst case: } \\
\text { Minimum target = upper limit of number } \\
\text { of recruits. }\end{array}$ & \\
\hline \multirow[t]{2}{*}{$\begin{array}{l}\text { Established } \\
\text { population }\end{array}$} & Population size. & $\begin{array}{l}\text { Sampling error (mean } \\
\text { and standard deviation } \\
\text { of sample). }\end{array}$ & $\begin{array}{l}\text { Confidence interval of } \\
\text { population size estimate. }\end{array}$ & $\begin{array}{l}\text { Assume worst case: population defined } \\
\text { by upper confidence limit. }\end{array}$ & \\
\hline & Number to remove. & $\begin{array}{l}\text { Combine abundance } \\
\text { with recruitment rate. }\end{array}$ & $\begin{array}{l}\text { Confidence interval of } \\
\text { number of recruits. }\end{array}$ & $\begin{array}{l}\text { Set cull target according to worst case: } \\
\text { Minimum target = upper limit of number } \\
\text { of recruits. }\end{array}$ & Ward \& Lees 2011 \\
\hline
\end{tabular}


Table 2. Feral wild boar population size estimates, cull targets and cull returns for the Forest of Dean, western England.

\begin{tabular}{|c|c|c|c|c|c|}
\hline Year & $\begin{array}{c}\text { Mean } \\
\text { population } \\
\text { estimate }\end{array}$ & $\begin{array}{c}\mathbf{9 5 \%} \\
\text { confidence } \\
\text { interval }\end{array}$ & $\begin{array}{c}\text { Advised cull } \\
\text { target }\end{array}$ & $\begin{array}{c}\text { Cull } \\
\text { achieved }\end{array}$ & Sources \\
\hline 2014 & 819 & 506-1325 & & 361 & Gill 2014 * \\
\hline 2015 & 1081 & $696-1486$ & 460 & 543 & $\begin{array}{l}\text { Gill \& Ferryman } \\
\text { 2015, Gill \& } \\
\text { Waeber } 2016^{*}\end{array}$ \\
\hline 2016 & 1562 & $1095-2296$ & 712 & 492 & $\begin{array}{c}\text { Gill \& Waeber } \\
2016^{*}\end{array}$ \\
\hline 2017 & & & & 477 & $*$ \\
\hline 2018 & 1635 & $1200-2228$ & & & $\begin{array}{c}\text { Gill \& Waeber } \\
2018\end{array}$ \\
\hline
\end{tabular}

* In 2014-2017, sources also included:

https://www.forestryengland.uk/article/more-information-about-wild-boar 
Fig. 1. Conceptual model of female cull target setting given estimates of female population size and female recruitment rate. $A$ is the mean of the female population size estimate, $B$ is the mean of the female recruitment rate estimate. Heavy dashed lines are the confidence limits of these estimates. Line $\mathrm{C}$ describes products of values for population size and recruitment rate that yield the same value as the product of the means (d). Point e is the intersection of upper confidence limits, which conceptually defines the lowest cull target to be sufficiently confident that at least the number of females recruited to the population will be removed, if it is achieved. Point $\mathrm{f}$ is the intersection of the lower confidence limits, which conceptually defines the highest cull target to be sufficiently confident that no more than the number of females recruited to the population will be removed, if it is achieved. 


\section{Box. Measures of quantities and uncertainty}

\section{Box. Measures of quantities and uncertainty}

Fowler et al. (1998), in their standard undergraduate text book on statistics for biologists, describe the following measures of uncertainty that have commonly been used in applied ecology for normally distributed data. Our interpretation is included in italics:

Arithmetic mean or mean - the sum of a set of observations divided by the number of observations.

Standard deviation - a measure of the degree of variability within a sample.

Standard error - the standard deviation of a set of sample means. The standard error is an indication of how close the sample mean is likely to be to the population mean. Thus, the standard error is an appropriate measure of uncertainty of an estimated parameter, but should not be used to describe variability in a sample.

Relative standard error (also known as the relative standard deviation, relative standard uncertainty or coefficient of variation) - the ratio of the standard deviation to the mean.

Confidence interval - The likely interval for the true population mean. If all possible $95 \%$ confidence intervals are calculated from un-biased samples taken from a population, the true value of the mean will be within the interval of 95\% of them (Neyman 1937).

The corresponding values reported for non-normally distributed data are the median and some proportion of the range (typically the 2.5 th and 97.5 th percentiles, or the full range of values measured).

\section{References}

Fowler J, Cohen L, Jarvis P $\left(1998,2^{\text {nd }}\right.$ ed.) Practical Statistics for Field Biology. John Wiley and Sons Ltd., Chichester, UK.

Neyman J (1937) Outline of a theory of statistical estimation based on the classical theory of probability. Philosophical Transactions of the Royal Society A 236: 333-380. 
SUPPORTING INFORMATION

Additional supporting information may be found in the online version of this article at the publisher's website.

Appendix S1. Methods for the review of adaptive management literature.

Appendix S2. Data from the review of adaptive management literature. 